\title{
Quadro teórico das presidências interrompidas - Uma revisão da literatura de remoção de presidentes $^{1}$
}

\author{
Theoretical framework of interrupted presidencies - A review of the literature on \\ the removal of presidents
}

\section{Bruno Martins Pessoa ${ }^{2}$}

Universidade de São Paulo, Brasil

\begin{abstract}
RESUMO O que explica a saída forçada antes do término do mandato de presidentes democraticamente eleitos? O objetivo desse artigo é fazer uma revisão da literatura de remoção de presidentes, e discutir os pontos de convergência e divergência dessa literatura, que surgiu nos últimos 20 anos e vem ganhando cada vez mais importância com o surgimento de novos casos de líderes eleitos que saíram antes do esperado, especialmente na América Latina.
\end{abstract}

PALAVRAS - CHAVE Impeachment; Presidencialismo; Remoção; Crise.

ABSTRACT What explains the forced departure of democratically elected presidents before the end of their term? The purpose of this article is to review the literature on the removal of presidents and discuss the points of convergence and divergence in this literature. This topic of discussion has emerged in the last 20 years and has gained increasing importance with new cases of elected leaders who have left office earlier than expected, especially in Latin America.

KEYWORDS Impeachment; Presidentialism; Removal; Crisis.

1. Este artigo é fruto do capítulo 1 da minha dissertação de mestrado PESSOA (2019).

2. Mestre e Doutorando no programa de pós-graduação do Departamento de Ciência Política da Universidade de São Paulo. Mail: brunopessoa@usp.br. 
RESUMEN ¿Qué explica la salida forzada antes del final del mandato de los presidentes elegidos democráticamente? El propósito de este artículo es revisar la literatura de remoción del presidente y no institucionales" y discutir los puntos de convergencia y divergencia en esta literatura, que ha surgido en los últimos 20 años y viene ganando cada vez más importancia con la aparición de nuevos casos de líderes electos que se fueron antes de lo esperado, especialmente en América Latina.

PALABRAS CLAVE Impeachment; Presidencialismo; Remoción; Crisis.

\section{Introdução}

O que explica a saída forçada antes do término do mandato de presidentes democraticamente eleitos? O objetivo desse artigo é fazer uma revisão da literatura de remoção de presidentes, fazer crítica a certos conceitos empregados, como os "fatores institucional e não institucional" e discutir os pontos de convergência e divergência dessa literatura, que surgiu nos últimos 20 anos e vem ganhando cada vez mais importância com o surgimento de novos casos de líderes eleitos que saíram antes do esperado, especialmente na América Latina.

Essa literatura surge a partir dos estudos em perspectiva comparada do presidencialismo, os quais travaram, nos últimos anos, intensos debates sobre as virtudes e defeitos desse sistema. Essa discussão chegou ao auge durante a Terceira Onda ${ }^{3}$ de democratização que marcou o fim de regimes autoritários, na América Latina e em outras partes do mundo, com a questão central sobre qual sistema de governo era o mais adequado para ser adotado nos países em transição para a democracia.

A despeito das inúmeras críticas ao presidencialismo, sua adoção na maior parte dos países da Terceira Onda, era justificada pelas características de legitimidade dual, sobrevivência independente dos poderes Executivos e Legislativo e o mandato fixo dos políticos eleitos que deveriam ter como efeito o aumento da estabilidade do governo. O impeachment do presidente, único mecanismo constitucionalmente reconhecido para a saída prematura do cargo, era tido como algo virtualmente impossível, dada sua dificuldade de ativação ${ }^{4}$.

Contudo, ao contrário desse diagnóstico, testemunhou-se a ocorrência de diversos presidentes popularmente eleitos que renunciaram ou foram removidos de seus cargos antes do término de seus mandatos, desafiando a definição de mandato fixo do presidencialismo e as previsões teóricas feitos pelos acadêmicos.

3. HUNTINGTON (1994).

4. LINZ (1994); SHUGART y CAREY (1992). 
Apesar da relevância desse fato, os trabalhos dentro do campo do presidencialismo que focam nesse fenômeno, denominado invariavelmente como presidential removal $^{5}$, presidential failure ${ }^{6}$, presidential fall ${ }^{7}$, interrupted presidency ${ }^{8}$ e presidential breakdown ${ }^{9}$ passaram a estudar esses acontecimentos, de uma maneira mais sistemática, somente há poucos anos.

O fenômeno de interesse desses estudos é definido como presidentes eleitos democraticamente que não completaram seus mandatos constitucionais, retirados por mecanismos institucionais, como impeachment, declaração de incapacidade, abandono de cargo, ou que renunciaram mediante pressão por sua saída, sem que haja ruptura democrática. A saída prematura do presidente é descrita na literatura como resultado de uma interação entre fatores políticos e sociais. Há divergências sobre a influência e peso de alguns desses fatores entre os estudos, porém, as variáveis explicativas são, em sua maioria, comuns nestes trabalhos.

Dessa forma, faremos um balanço dessa incipiente e crescente literatura, discutindo suas controvérsias analíticas e normativas, traçando o quadro teórico e suas fronteiras. $\mathrm{O}$ artigo está estruturado da seguinte forma. Na seção 1 trazemos o quadro teórico da remoção presidencial. Em seguida, na seção 2 fazemos a discussão de causas das divergências dentro da literatura. Na seção 3 mostramos os diferentes mecanismos institucionais utilizados e por fim as considerações finais.

\section{Quadro Teórico de Remoção Presidencial}

A literatura dentro do estudo do sistema presidencialista que se dedica à remoção presidencial surge em meados dos anos 2000, com a obra editada por Baumgartner e Kada (2003) que inaugura esse debate e analisa o fenômeno pelas lentes do impeachment. Antes de 1990, eram raros os casos de presidentes que haviam sido removidos por esse procedimento ou mesmo que enfrentaram tentativas de impeachments fora dos Estados Unidos ${ }^{10}$.

Essa obra teve por méritos investigar os fatores políticos que afetavam as chances de tentativas de impeachment ao estudar casos ao redor do mundo entre 1990 a 2001, período em que esse mecanismo foi acionado diversas vezes, e, a despeito de sua ên-

5. PÉREZ-LIÑÁN (2007; 2014).

6. HOCHSTETLER y EDWARDS (2009); MARTÍNEZ (2017); HOCHSTETLER y SAMUELS (2011).

\section{HOCHSTETLER (2006).}

8. KIM y BAHRY (2008); NEGRETTO (2006); MARSTEINTREDET y BERNTZEN (2008); VALENZUELA (2004); MARSTEINTREDET(2014).

9. LLANOS Y MARSTEINTREDET (2010c); HOCHSTETLER (2011).

10. Os casos de impeachment, fora dos EUA, foram Equador, 1933 e Panamá, 1955 MARSTEINTREDET y BERNTZEN (2008). 
fase em dimensões políticas, também trouxe à discussão, ainda que de uma maneira marginal, fatores sociais que deveriam ser considerados na análise.

A partir desse trabalho, houve uma gradual transição para estudos analíticos que passaram a olhar uma justaposição de fatores políticos e sociais, o que acabou tornando-se o quadro teórico dominante para se pensar a saída prematura de presidentes. Ademais, os trabalhos subsequentes passaram a ter como maior foco os países da América Latina, devido ao maior número de ocorrências na região ${ }^{11}$.

À medida que a literatura se desenvolvia e ampliava seu escopo, trazendo estudos de casos, percebeu-se que muitos deles não se enquadravam na categoria institucional de impeachment. A produção científica da área, já no início da expansão do campo, chegou à conclusão de que as causas do impeachment e de outras formas de remoção, como a renúncia mediante pressão ou declaração de incapacidade, eram similares o suficiente para serem tratadas como um único fenômeno mais amplo, a remoção presidencial. As diferentes formas de saída do presidente se davam por questão contingencial e de expediente à disposição dos atores políticos ${ }^{12}$.

O pano de fundo dessa literatura é a análise das remoções presidenciais como casos desviantes da definição clássica do presidencialismo e o ponto de partida é a obra seminal de Linz (1978). Em um contexto em que as rupturas democráticas eram regra na América Latina, Linz iniciou o debate sobre o presidencialismo com críticas referentes às características do sistema, quais sejam, o mandato fixo e eleições diretas e independentes do Executivo e Legislativo, que dariam legitimidade democrática dual entre os poderes. Dessa configuração institucional derivaria falta de incentivos para a cooperação entre o presidente e o parlamento. Ademais, o sistema presidencialista multipartidário seria mais propenso a presidentes minoritários e, somando-se aos fatores acima descritos, não haveria solução democrática para impasses entre os poderes, sendo necessário recorrer a instrumentos não constitucionais, o que levaria à quebra da democracia.

O diagnóstico de Linz sobre os defeitos do sistema presidencialista aumentarem as chances de ruptura democrática -amplamente debatido e criticada na literatu$\mathrm{ra}^{13}$ - não se confirmou. A partir da Terceira Onda de democratização, com início em 1978, 30\% dos presidentes eleitos democraticamente no mundo enfrentaram crises e pressões pelas suas saídas do cargo e $12 \%$ falharam em cumprir integralmente seus mandatos até 2006, com novos casos surgindo após esse período ${ }^{14}$.

11. Para exceções, ver KIM y BAHRY (2008); BAUMGARTNER y KADA (2003); HOCHSTETLER y EDWARDS (2009).

12. HOCHSTETLER (2011); HOCHSTETLER y EDWARDS (2009); PÉREZ-LIÑÁN (2007).

13. CHEIBUB Y LIMONGI (2002); CHEIBUB (2002).

14. HOCHSTETLER y SAMUELS (2011); MARTÍNEZ (2017); HOCHSTETLER (2006). 
Contudo, o regime democrático permaneceu intacto, com raras exceções. Com a mudança no contexto político internacional, passou-se a ter, conforme termo cunhado por Pérez-Liñán ${ }^{15}$, uma "nova instabilidade política" com a remoção ou saída de presidentes de seus cargos, mas com a manutenção da democracia, em contraposição à "antiga instabilidade", que resultava na instauração de regimes autoritários.

Porém, o modelo teórico de Linz $(1978 ; 1994 ; 1990)$, foi transportado para os estudos de remoção presidencial por parte dos pesquisadores a fim de explicar essa nova forma de instabilidade. Se o mau funcionamento e performance das instituições no sistema presidencialista para a implementação e solução de conflitos levariam à ruptura democrática, as causas para a remoção presidencial também derivariam dos vícios do presidencialismo, apesar de se tratar de fenômenos distintos ${ }^{16}$.

A pergunta, então, passou a ser: o que faz um presidente ser vulnerável à remoção presidencial? O primeiro movimento da literatura é analisar o surgimento de précondições necessárias que ameacem o chefe do Executivo e desestabilizem o governo, gerando uma crise que leve aos chamados desafios. Desafio é definido como ação concreta para convencer o presidente a renunciar ou forçar sua saída do cargo antes do término do mandato ${ }^{17}$. Nesse cenário de saída prematura do presidente com a manutenção do regime democrático, houve uma troca de papéis quanto ao autor do desafio. Com a retirada dos militares do jogo político, os atores que levam os desafios ao presidente passam a ser civis. Sua origem, então, pode ser da sociedade civil ou do Legislativo, o que faz com que o desafio seja caracterizado pela literatura como político, social ou uma combinação a partir de uma interação entre ambos ${ }^{18}$.

Para que os desafios sejam lançados pelos atores civis, se faz necessária a presença dos fatores políticos e sociais que aumentam o risco de remoção presidencial, porém o sucesso - com a saída do presidente - ou a falha - com a manutenção do mandato do desafio depende do grau de variação desses fatores. Podemos dizer que os fatores políticos afetariam a capacidade dos atores de irem contra o presidente, enquanto os fatores sociais afetariam suas motivações ${ }^{19}$. Vejamos então quais são esses fatores e de que forma elas atuariam.

15. PÉREZ-LIÑÁN (2007; 2014); PÉREZ-LIÑÁN y POLGA-HECIMOVICH (2017).

16. ÁLVAREZ y MARSTEINTREDET (2010); VALENZUELA (2004); MARSTEINTREDET(2014).

17. HOCHSTETLER (2006); HOCHSTETLER y EDWARDS (2009).

18. ÁLVAREZ y MARSTEINTREDET (2010); PÉREZ-LIÑÁN (2007).

19. HOCHSTETLER y EDWARDS (2009). 


\subsection{Fatores Políticos e Sociais}

Uma crítica feita neste trabalho refere-se à nomenclatura utilizada pelo campo. Os autores referem-se aos fatores como, "institucional" e "não institucional", o que traz uma imprecisão dos termos. Em muitos momentos, quando a literatura utiliza "institucional”, está se referindo a fatores políticos. O mais adequado seria nomeá-los fatores políticos e fatores sociais. Por ser a remoção de presidente uma medida excepcional, comparado ao sistema parlamentarista, ela não pode ser institucional nesse sentido. As remoções serão tratadas dentro das instituições preexistentes e não se iniciarão por razões institucionais per se. Ademais, ao lançar mão dessa nomenclatura, gera-se uma confusão quando alguns acadêmicos efetivamente avaliam o arcabouço institucional como uma dimensão importante para a remoção, haja vista que as instituições moldam a competição política, estabelecendo um equilíbrio na interação, e afetam as estratégias dos atores políticos envolvidos ao se adequarem às regras vigentes.

Segundo a literatura, uma das motivações dos atores civis para lançarem mão de desafios ao presidente é a descoberta de escândalos políticos. Escândalos são definidos como eventos noticiados que revelam episódios de corrupção e/ou abuso de poder pelas autoridades públicas ${ }^{20}$. Para terem esse efeito, os escândalos dependeriam da exposição sistemática da mídia ${ }^{21}$.

A economia, em um primeiro momento, é considerada nas análises como riscos à manutenção do cargo do chefe do Executivo $^{22}$. Contudo, dentro da literatura, o fator social mais destacado é a mobilização social, com protestos de rua ${ }^{23}$. O status legislativo minoritário de cadeiras controladas pelo partido do presidente ou sua coalizão partidária, apontado como fator importante para a manutenção do cargo, é destaque e ponto comum aos trabalhos do campo ${ }^{24}$.

Se a falta de apoio amplo no Congresso é uma dimensão que afeta as chances de queda do presidente, parte da literatura de remoção presidencial passou a considerar a fragmentação partidária como fator político capaz de afetar o resultado ${ }^{25}$. Em

20. PÉREZ-LIÑÁN (2007); KIM (2014); HOCHSTETLER (2006).

21. PÉREZ-LIÑÁN (2007); LLANOS y MARSTEINTREDET (2010b).

22. PÉREZ-LIÑÁN (2007); KIM y BAHRY (2008); HOCHSTETLER (2006); HOCHSTETLER y EDWARDS (2009); ÁLVAREZ y MARSTEINTREDET (2010).

23. HOCHSTETLER y EDWARDS (2009); PÉREZ-LIÑÁN (2007); HOCHSTETLER (2006).

24. HOCHSTETLER (2006; 2011); HOCHSTETLER y SAMUELS (2011); PÉREZ-LIÑÁN (2014); 2007); KIM (2014); KIM y BAHRY (2008); MARTÍNEZ (2017); HOCHSTETLER y EDWARDS (2009); LLANOS y MARSTEINTREDET (2010C); NEGRETTO (2006); MARSTEINTREDET y BERNTZEN (2008).

25. KIM y BAHRY (2008); ÁLVAREZ y MARSTEINTREDET (2010); NEGRETTO (2006). 
menor grau, alguns trabalhos no campo ainda acrescentam como fator institucional a distribuição de poderes entre o presidente e o Legislativo como dimensão que aumentaria a probabilidade de conflitos e crises e, por conseguinte, as chances de remoção presidencial ${ }^{26}$.

Dissemos que a forma de remoção pode variar por questão de contingência e de expediente. Nesse caso, a atenção se volta para as regras institucionais inseridas no desenho constitucional, como o impeachment, a declaração de incapacidade e o abandono do cargo. Os procedimentos para a ativação e efetivação dessas ferramentas legais, como a quantidade de votos necessários para remover o presidente, foram trazidas pela literatura como fator institucional ${ }^{27}$.

Quando há remoção presidencial, em regra, as constituições presidencialistas preveem a linha sucessória em caso de vacância do cargo. Normalmente cabendo esse papel ao vice-presidente. Assim, em especial quando o desafio parte do Legislativo, a figura de quem assume a presidência é incorporada nas pesquisas ${ }^{28}$. À luz dos fatores apresentados até esse momento, temos que o presidente é, ao menos em parte, responsável pelo seu próprio destino. As estratégias adotadas pelo chefe do Executivo em estabelecer seu relacionamento com o Congresso ${ }^{29}$ e lidar com os protestos de rua são consideradas como dimensão saliente para a remoção do presidente ${ }^{30}$.

A variação do grau de suporte à disposição do presidente, seja com sua constituency ou no Legislativo, parece dar a tônica do sucesso ou falha dos desafios. Dado o leque de fatores levados em consideração, não é de se estranhar que a remoção presidencial seja tida como um evento complexo e difícil de ser totalmente capturado por modelos estatísticos, devido ao número baixo de casos e o alto número de variáveis independentes. Nem mesmo os estudos qualitativos do campo foram capazes de estabelecer em definitivo um mecanismo causal convincente que captasse a interação desses fatores que levaria à interrupção do mandato.

Em razão disso, é possível vislumbrar, grosso modo, dois tipos de perspectivas empregadas na literatura para explicar o fenômeno, que se diferenciam na ênfase quanto à importância chave dos tipos de fatores para a saída prematura de presidentes: uma perspectiva política que afirma que os fatores políticos são os mais importantes e

26. KIM (2014); KIM y BAHRY (2008); MARTÍNEZ (2017).

27. PÉREZ-LIÑÁN (2007); KIM (2014); KIM y BAHRY (2008); MARSTEINTREDET y BERNTZEN (2008).

28. LLANOS y MARSTEINTREDET (2010A); PÉREZ-LIÑÁN (2007); LLANOS y MARSTEINTREDET (2010b).

29. PÉREZ-LIÑÁN (2007); LLANOS y MARSTEINTREDET (2010a).

30. HOCHSTETLER (2006); HOCHSTETLER y EDWARDS (2009). 
outra perspectiva social, que defende a maior importância dos fatores sociais na remoção do presidente.

De que maneira, então, esses fatores elencados acima afetariam as chances de sobrevivência do chefe do Executivo? Ao analisar o papel dos escândalos de corrupção, parte da literatura afirma que, mesmo quando ainda restritos às figuras dentro da administração do Executivo, enfraquecem e corroem a credibilidade do governo que passa a ter que lidar com esse problema, tirando o foco de ações governamentais cruciais e, ao atingir diretamente a figura do presidente, desviam a atenção da agenda de governo e faz com que haja uma progressiva perda de aprovação pública. A perda de aprovação de um governo é um fenômeno comum, porém o nível de deterioração é maior nos casos de tentativas de remoção ${ }^{31}$.

Os escândalos, por vezes, unem o Congresso e a sociedade civil para desafiar o presidente quando há evidências claras e sólidas que o envolvam diretamente. Quanto mais politicamente efetivo for o caso revelado ao público, ou seja, quanto mais indignação pública o caso trouxer, maiores são os riscos ao presidente. Nesse cenário, a escalada de descontentamento público dá combustível para desafios como protestos de rua que pedem sua saída incentiva tentativas de impeachment por legisladores oposicionistas que, ao constatar sua fragilidade veem os custos de enfrentamento reduzidos ${ }^{32}$.

Contudo, a importância dos escândalos de corrupção como variável explicativa no surgimento de desafios, sejam da sociedade civil ou do Congresso, depende de outros fatores. Um caso isolado de corrupção é improvável que gere uma crise de opinião pública. Para isso, é necessária uma exposição sistemática que não se dá pelo acaso. Depende-se do papel da mídia, que varia de acordo com o seu grau de profissionalização e liberdade na divulgação, e às vezes de investigação, dos fatos que envolveriam corrupção e malfeitos do presidente e de pessoas próximas a ele $^{33}$.

A mídia não atua isolada do contexto político em que se encontra. Editores e meios de comunicação em massa seguem considerações estratégicas e tendem a engajar investigações de escândalos em administrações fracas e em cenários de baixa aprovação presidencial. Da mesma forma, políticos oposicionistas se aproveitam dessa debilidade do presidente para vazar à mídia informações sensíveis das investigações institucionais, resultando em uma retroalimentação desses fatores ${ }^{34}$. Os escândalos

31. BAUMGARTNER y KADA (2003); HOCHSTETLER (2006); PÉREZ-LIÑÁN (2007).

32. BAUMGARTNER y KADA (2003); HOCHSTETLER (2006); HOCHSTETLER y EDWARDS (2009); KIM (2014); PÉREZ-LIÑÁN (2007).

33. BAUMGARTNER y KADA (2003); KIM (2014); LLANOS y MARSTEINTREDET (2010b); NOVARO (2015); PÉREZ-LIÑÁN (2007).

34. PÉREZ-LIÑÁN (2007); HOCHSTETLER y EDWARDS (2009); HOCHSTETLER (2006). 
de corrupção e da cobertura da mídia sobre esses eventos são apontados por parte da literatura como fatores capazes de aumentar as chances de ocorrerem desafios ao presidente, mas apenas em menor grau afetam as chances de remoção presidencial ${ }^{35}$.

Esses fatores só influenciariam nos desafios vindo das ruas à medida que são capazes de encorajar mobilizações sociais para protesto contra o presidente e, mesmo assim, a relação entre escândalos de corrupção e protestos de rua não se dá de forma direta. O espaço entre a insatisfação popular e a mobilização é preenchido ou não pela variedade de recursos presentes na sociedade, como organizações sociais e mobilizadores capazes de canalizar essa insatisfação em protestos. Ou seja, onde já há essa estrutura mobilizadora, como sindicatos, grupos classistas, sociedade civil organizada, união de estudantes, etc., as chances de haver protestos contra o presidente aumentam ${ }^{36}$.

Da mesma maneira, a despeito da corrupção e abuso de poder serem previstos legalmente como infrações passíveis de impeachment do presidente, se não houver um ambiente propício no Legislativo que permita um comportamento proativo dos parlamentares - nesse caso, o status minoritário do presidente no Congresso e uma relação conflituosa entre os poderes -, haverá apenas um aumento nas chances de haver tentativas de remoção por essa via, mas seu impacto no sucesso do impeachment é menor ${ }^{37}$. Outros trabalhos da área discordam dos efeitos dos escândalos com a constatação de haver casos de presidentes que conseguiram sobreviver no cargo apesar de se verem envolvidos em casos de corrupção ${ }^{38}$.

A avaliação divergente do impacto desses fatores na remoção presidencial prossegue em relação ao debate do peso do fator econômico. A economia sempre foi considerada relevante nas análises de sobrevivência de regimes democráticos. Isso fez com que as pesquisas de remoção presidencial dessem atenção a essa variável e seus possíveis efeitos sobre a probabilidade de o presidente sobreviver no cargo. Os resultados de alguns trabalhos corroboraram o pensamento intuitivo de que presidentes de países ricos possuem mais chances de concluir seus mandatos do que suas contrapartes $^{39}$.

35. PÉREZ-LIÑÁN (2007); HOCHSTETLER (2006); HOCHSTETLER y EDWARDS (2009); KIM (2014); PÉREZ-LIÑÁN (2014).

36. HOCHSTETLER (2006); HOCHSTETLER y EDWARDS (2009).

37. KIM (2014); PÉREZ-LIÑÁN (2007).

38. Alguns exemplos de presidentes que foram removidos envoltos em caso de corrupção são Carlos Andrés Pérez (Venezuela, 1993) e Fernando Collor de Mello (Brasil, 1992). Já alguns exemplos de presidentes que sobreviveram aos escândalos de corrupção, temos Ernesto Samper (Colômbia, 1996) e Ménem (Argentina, 1999). MARTÍNEZ (2017); KIM y BAHRY (2008).

39. ÁLVAREZ y MARSTEINTREDET (2010). 
Uma má performance econômica, mais especificamente os seus efeitos decorrentes, como o aumento do desemprego, queda na renda e aumento nas desigualdades, afetam negativamente a popularidade do presidente, que é visto como o responsável pela implementação e gestão econômica. Nesse passo, o desempenho econômico teria o mesmo papel dos escândalos de corrupção ${ }^{40}$.

Justamente por isso, alguns autores chegaram a afirmar que a implementação de reformas econômicas neoliberais significava um risco para a permanência do presidente no cargo $^{41}$. Contudo, essa linha econômica, por si só, não explicaria a remoção presidencial e a ideia central seria a mesma, uma insatisfação da população com a política econômica do governo. Ademais, não explicaria a queda de presidentes de esquerda, com linha política econômica oposta ${ }^{42}$. Como os escândalos, o fator econômico não levaria diretamente aos desafios vindos das ruas. A má performance econômica só afeta as chances de sobrevivência do presidente se também for capaz de traduzir essa insatisfação em mobilizações sociais, com protestos de rua que dependem da mesma estrutura mobilizadora descrita acima ${ }^{43}$.

Além disso, seu impacto nos desafios políticos não é considerado relevante por algumas pesquisas. Apesar do presidente ser responsável pela economia, o Congresso também pode ser responsabilizado pela população e, ademais, os parlamentares têm dificuldades em enquadrar falhas econômicas como ofensas passíveis de impeachment ${ }^{44}$. Alguns acadêmicos argumentam que o contexto econômico que caracteriza a maior parte das remoções presidenciais não é um problema per se, mas sim a forma como a questão econômica é gerida pelo governo que é capaz de criar insatisfação popular ${ }^{45}$.

Martínez (2017) vai além ao afirmar que a performance econômica não tem nenhum impacto na remoção presidencial quando se incorpora na análise o tempo em que um país está sob o regime democrático. Não obstante, encontramos problemas econômicos em diversos países presidencialistas em que seus chefes de Executivo completaram os mandatos sem maiores dificuldades. Outra consequência seria a imunidade que presidentes acusados diretamente em escândalos de corrupção e abu-

40. PÉREZ-LIÑÁN (2007); HOCHSTETLER (2006); HOCHSTETLER y EDWARDS (2009); HOCHSTETLER (2011); KIM y BAHRY (2008); LLANOS (2010); KIM (2014).

41. HOCHSTETLER (2006); PÉREZ-LIÑÁN (2007); LLANOS y MARSTEINTREDET (2010b).

42. HOCHSTETLER y EDWARDS (2009); LLANOS y MARSTEINTREDET (2010a).

43. HOCHSTETLER (2006); HOCHSTETLER y EDWARDS (2009); PÉREZ-LIÑÁN (2007); ACOSTA y POLGA-HECIMOVICH (2010).

44. KIM (2014); PÉREZ-LIÑÁN (2007); LLANOS y MARSTEINTREDET (2010a).

45. ACOSTA y POLGA-HECIMOVICH (2010); LLANOS y MARSTEINTREDET (2010a). 
so de poder desfrutariam contra a remoção presidencial, se tivessem um desempenho econômico satisfatório, enquanto suas contrapartes que não estivessem envolvidos em nenhum malfeito estariam mais vulneráveis quando a economia estivesse em declínio ${ }^{46}$.

O surgimento de desafios mostra que o descontentamento com a figura do presidente pode ser uma resposta legítima a casos de corrupção, o descontentamento com uma política pública ou mesmo manipulação da mídia num contexto de crise governamental. Como também pode ser uma convergência de todos esses fatores de uma só vez. Quando os desafios são oriundos das ruas, esses fatores funcionam como a motivação para a desaprovação popular que pode se converter em protestos massivos voltados contra a permanência do presidente.

O protesto de rua demandando a saída do presidente é o fator em que as divergências e debates na literatura geram maior discussão quanto ao seu peso na remoção presidencial. Para a perspectiva social, seu papel teria substituído aquele desempenhado pelo poder militar nas rupturas democráticas, constituindo-se num "novo poder moderador" dentro dos novos regimes democráticos civis. Nenhum desafio seria bem sucedido sem a presença de protestos ${ }^{47}$.

Em contextos de baixa institucionalização e de um governo fraco, esses protestos contra o presidente demonstrariam a indisposição popular de se esperar até a próxima eleição para a troca de comando do Executivo. E, quando ligado a um ativismo legislativo, afetaria a motivação dos parlamentares de proteger ou abandonar o presidente, alterando os custos de cada escolha de ação e daria suporte ao Congresso para avançar ou iniciar investigações ${ }^{48}$.

Contudo, não se trata de qualquer manifestação popular que leva ao sucesso dos desafios presidenciais. Greves e outras mobilizações com demandas mais difusas não afetam as chances de sobrevivência do presidente. A mobilização social para ter sucesso deve se voltar diretamente contra o presidente e deve ser capaz de formar uma grande coalizão social entre a classe média e setores populares, caso contrário, seu impacto será insignificante para a remoção presidencial ${ }^{49}$. Uma repressão violenta

46. PÉREZ-LIÑÁN (2007); KIM (2014).

47. HOCHSTETLER (2006); HOCHSTETLER y EDWARDS (2009); HOCHSTETLER (2011); PÉREZ-LIÑÁN (2007).

48. ACOSTA y POLGA-HECIMOVICH (2010); BAUMGARTNER y KADA (2003); BUITRAGO (2010); HOCHSTETLER (2006, 2011); HOCHSTETLER y EDWARDS (2009); HOCHSTETLER y SAMUELS (2011); KIM (2014); KIM y BAHRY (2008); PÉREZ-LIÑÁN (2007).

49. PÉREZ-LIÑÁN (2014; 2007); HOCHSTETLER y EDWARDS (2009); ÁLVAREZ y MARSTEINTREDET (2010); LLANOS y MARSTEINTREDET (2010a). 
dos protestos por parte do governo, com morte de manifestantes, também é apontada como fator de efeito relevante na variável dependente ${ }^{50}$.

Fica claro que, para a corrente que enfatiza o peso dos fatores sociais, a sequência de eventos é iniciada com o enfraquecimento da administração do presidente - como escândalos e má performance econômica, que levam aos protestos, organizados pela sociedade civil - e a atuação dos fatores políticos viria num segundo momento, em reposta aos desafios das ruas, de forma reativa e a reboque das manifestações.

A perspectiva que enfatiza os fatores políticos reconhece a influência e o papel desempenhado pelos protestos de rua quanto ao enfraquecimento de uma presidência, porém, sem descartá-los, afirma que é a ação político-legislativa e não a mobilização social a principal força para o colapso de administrações presidenciais ${ }^{51}$. Essa diferença sequencial parece ser um dos motivos (mas não o único) que leva à discordância entre as perspectivas em relação ao peso das variáveis no resultado da remoção presidencial.

Além da existência de contrafactuais, com presidentes que foram removidos sem a presença de manifestações nas ruas ${ }^{52}$, a própria ideia dos protestos como fator desequilibrante e condicionante do comportamento de atores políticos é questionada por essa corrente. Autores apontam para a dificuldade de escapar da imagem de políticos experientes e estruturas partidárias tradicionais atuando para ativar suas próprias redes de mobilização a fim de transformar a indignação pública em protestos, capitalizando esses movimentos para seus próprios interesses ${ }^{53}$. Ademais, o efeito dos protestos de rua perde força quando controlado pelo "estoque democrático" ${ }^{54}$, ao apontar um alto nível institucional da democracia para o país ${ }^{55}$.

Para a perspectiva política, quando a insatisfação com o governo atinge as ruas, significa que a coalizão do presidente já não garante a estabilidade política. O fim prematuro da administração sinalaria uma ruptura na cooperação e interação entre

50. HOCHSTETLER (2006); HOCHSTETLER y EDWARDS (2009); BUITRAGO (2010).

51. LLANOS y MARSTEINTREDET (2010a); PÉREZ-LIÑÁN (2014); MARTÍNEZ (2017).

52. O presidente paraguaio Fernando Lugo sofreu um processo de impeachment concluído em 48 horas que determinou sua saída do cargo, sem que houvesse nenhuma manifestação contrária à sua permanência, em junho de 2012.

53. NOVARO (2015); PÉREZ-LIÑÁN (2007); LLANOS y MARSTEINTREDET (2010a); FIGUEIREDO (2010).

54. MARTÍNEZ (2017) adota a ideia de estoque democrático desenvolvida por Gerring a fim de incorporar na análise os efeitos de longos períodos em que um país se encontra sob o regime democrático.

55. MARTÍNEZ (2017). 
presidente e Congresso, com os protestos sendo o último fator dentro da corrente de eventos que leva à remoção e com seus efeitos mediados pelo Legislativo, atribuindo, assim, um maior peso aos fatores políticos ${ }^{56}$.

Em sistemas presidencialistas, Executivo e Legislativo regularmente estão em confronto ao tratar de políticas públicas, negociando e desafiando um ao outro sobre essas questões. Isso é a política normal em que grupos opostos buscam acordos de compromisso e não geram crises de governabilidade. Para a literatura, a remoção presidencial ocorre dentro das chamadas crises presidenciais, que se referem a casos extremos de conflitos Executivo-Legislativo em que o comportamento colaborativo das partes se torna impossível e cada poder tenta remover o outro ${ }^{57}$.

Sem a ruptura democrática, torna-se virtualmente impossível a dissolução do Congresso, o que faz com que crises presidenciais terminem invariavelmente com o Legislativo prevalecendo vis-à-vis o Executivo. Para a literatura comparada, o governo minoritário aumentaria as chances de conflito e de travamento da agenda política sempre que o Executivo e Legislativo fossem controlados por partidos diferentes ${ }^{58}$.

A literatura de remoção presidencial constatou que os desafios são largamente direcionados a presidentes minoritários e o status partidário de assentos no Congresso é fator importante para explicar se eles são bem-sucedidos ou não ${ }^{59}$. Para legisladores opositores, lançar mão de desafios institucionais, como tentativas de impeachment, ou apoiar desafios das ruas pode ter uma série de ganhos políticos, mesmo que não haja a remoção, ao fazer com que ganhem poder de barganha e forcem o presidente a dar atenção para suas demandas ${ }^{60}$.

Contudo, algumas pesquisas no campo mostraram que o status minoritário do presidente no Congresso, por si só, não afetaria o comportamento colaborativo que resultaria no entrave Executivo-Legislativo e, por conseguinte, na remoção presidencial. O imobilismo não é um traço estrutural do sistema presidencialista quando se encontra em situações de divisão. Mesmo sem conseguir formar uma coalizão, go-

56. ÁLVAREZ y MARSTEINTREDET (2010); BUITRAGO (2010); KIM (2014); LLANOS y MARSTEINTREDET (2010c); MARTÍNEZ (2017); PÉREZ-LIÑÁN (2014).

57. PÉREZ-LIÑÁN (2007); NEGRETTO (2006); LLANOS y MARSTEINTREDET (2010b).

58. MAINWARING y SHUGART (1997); LINZ (1994); VALENZUELA (2004); SHUGART y CAREY (1992).

59. HOCHSTETLER (2006); LLANOS y MARSTEINTREDET (2010a); HOCHSTETLER y EDWARDS (2009); MARTÍNEZ (2017); HOCHSTETLER (2011); KIM (2014); KIM y BAHRY (2008); MARSTEINTREDET y BERNTZEN (2008).

60. HOCHSTETLER (2006); KIM (2014); MUSTAPIC (2010). 
vernos divididos podem evitar o entrave e, portanto, não tornam presidentes mais vulneráveis ${ }^{61}$.

Para Negretto (2006), mesmo presidências e coalizões minoritárias não trazem necessariamente risco à sobrevivência, se o presidente for capaz de manter o apoio do partido de veto, que controla os legisladores que permitem ao presidente manter o veto contra leis que não são de sua preferência; e do partido médio/mediano, que controla os legisladores cujas propostas não podem ser derrotadas por uma maioria legislativa, pois suas preferências estão na mediana do espectro ideológico dos partidos que compõem o Congresso. Sem esses apoios, haveria o risco de entraves e de se formar uma coalizão opositora majoritária capaz de desafiar o presidente. Quando os parlamentares de oposição conseguem formar essa coalizão, o risco de remoção presidencial cresce.

Na mesma linha, a fragmentação partidária e a desigualdade de distribuição de poderes entre presidente e Congresso encontram pouco suporte empírico na literatura. Com exceção de alguns trabalhos ${ }^{62}$, a fragmentação partidária não impacta nas chances de remoção presidencial, pois presidentes tendem a formar coalizões majoritárias para governar. Ademais, mesmo presidentes com fortes poderes legislativos não conseguem governar sem o apoio e contra a maioria do Congresso ${ }^{63}$.

A literatura comparada de presidencialismo mostra que o presidente detém o protagonismo na formação da coalizão ao dispor da prerrogativa para a nomeação de membros de outros partidos para compor os ministérios, dividindo a administração entre aliados que garantam o apoio no Congresso. As coalizões multipartidárias por sua vez, contribuem para a estabilidade dos governos e os partidos que participam se beneficiam do sucesso da administração ${ }^{64}$.

Porém, mesmo diante de condições institucionais favoráveis, alguns presidentes falham em manter o apoio da coalizão e a erosão em seu interior contribui para a instabilidade política e a crise no executivo. Há aumento no risco de remoção presidencial quando setores dentro das forças que apoiam o presidente decidem que é melhor abandoná-lo. Parlamentares são atores políticos estratégicos e a decisão de apoiar ou abandonar o presidente depende dos incentivos que cada uma dessas ações vai gerar $^{65}$.

61. CHEIBUB (2002); CHEIBUB (2007); NEGRETTO (2006); KIM y BAHRY (2008).

62. KIM y BAHRY (2008); KIM (2014); ÁLVAREZ y MARSTEINTREDET (2010).

63. LLANOS y MARSTEINTREDET (2010c); NEGRETTO (2006).

64. FIGUEIREDO y LIMONGI (1999); LIMONGI (2006); SANTOS (2006); FIGUEIREDO (2007); AMORIM NETO (2006); BATISTA (2016).

65. ACOSTA y POLGA-HECIMOVICH (2010); MUSTAPIC (2010); PÉREZ-LIÑÁN (2014; 2007). 
A sobrevivência da coalizão está atrelada, em uma dimensão, aos recursos finitos de incentivo à disposição de seus membros e, em outra dimensão, a percepção do seu valor ao longo do tempo. Os partidos aliados tendem a deserdar a coalizão se os benefícios estão abaixo da expectativa de utilidade desejada. Da mesma forma, à medida que o calendário eleitoral se aproxima, diante de uma administração fraca e o surgimento de pressão da mídia e desafios de rua exigindo a remoção presidencial, é pouco provável que os aliados queiram dividir o ônus político com o governo ${ }^{66}$.

Presidentes, mesmo sob acusações de corrupção expostas sistematicamente na mídia, deterioração da situação econômica e enfrentando protestos de rua pedindo suas saídas, podem sobrevir aos desafios, se puderem contar com o apoio de legisladores leais capazes de formar o que Pérez Liñán ${ }^{67}$ chamou de "escudo legislativo" para protegê-los. Esse escudo somente pode ser construído e mantido se o presidente for capaz de manter a coesão interna de sua coalizão e caso ela seja grande o suficiente para ser capaz de bloquear as manobras da oposição, vetando a remoção presidencial por via institucional e resistir ao impacto e mediar as forças das manifestações de rua contrárias à permanência do chefe do Executivo, aumentando o custo de energia requerida para desestabilizar o governo.

A construção e manutenção do "escudo legislativo" não se baseia somente em questões partidárias, mas também na liderança do presidente em cultivar apoio de atores do Legislativo. Mesmo que não seja o único ator envolvido, o Congresso desempenha um papel crítico para o sucesso ou falha dos desafios. A estratégia adotada pelo chefe do Executivo para lidar com o Legislativo, desde o primeiro dia de mandato, é fator determinante para moldar a resposta dos parlamentares diante das ameaças à sobrevivência no cargo. $\mathrm{O}$ presidente pode adotar três formas de relacionamento: optar por isolar-se em relação ao Congresso, quando tenta implementar políticas públicas ignorando as preferências dos parlamentares e ao não negociar com os partidos. Outra estratégia é o confronto, quando o presidente abertamente desafia o Legislativo para impor sua agenda, esperando angariar apoio da opinião pública e forçar o Congresso a se submeter a sua vontade. Por fim, o presidente pode optar por negociar com o Congresso e os partidos. Aqueles que estão mais dispostos a atender as necessidades dos parlamentares e partidos, mesmo os opositores, seja em termos de políticas públicas ou pork barrel, possuem mais chances de sobrevivência ${ }^{68}$.

66. ACOSTA y POLGA-HECIMOVICH (2010); LLANOS y MARSTEINTREDET (2010c); MUSTAPIC (2010); PÉREZ-LIÑÁN (2007; 2014).

67. PÉREZ-LIÑÁN (2007; 2014); PÉREZ-LIÑÁN y POLGA-HECIMOVICH (2017).

68. PÉREZ-LIÑÁN (2007); LLANOS y MARSTEINTREDET (2010a); MUSTAPIC (2010); FIGUEIREDO (2010). 
Um aspecto ainda pouco explorado dentro da literatura é o papel do vice-presidente. Quando surge um desafio, a figura do vice acaba tendo relevância estratégica. Nas constituições presidencialistas, nos casos de vacância do cargo, normalmente é a sua figura que assume a presidência dentro da linha sucessória. Parlamentares irão avaliar se quem assumir poderá colaborar e atender as demandas e preferências do Legislativo. Ademais, o vice tem poucos incentivos para permanecer ao lado do presidente ante os desafios. Se for um dos líderes de partido que compõem a coalizão, vislumbrando assumir o cargo e não compartilhar do mesmo destino do titular, pode trabalhar para esvaziar a base de apoio do presidente quando a relação entre eles é conflituosa ${ }^{69}$.

Nesse diapasão, um fator importante é incompreensivelmente ignorado pela literatura: o controle da presidência da Câmara ou do Congresso. Em muitas constituições presidencialistas, o presidente da Câmara ou Congresso possui poderes institucionais para pautar a agenda do Legislativo. Isso inclui o poder para instaurar comissões parlamentares de inquérito a fim de investigar escândalos de corrupção envolvendo o presidente, receber e decidir sobre denúncias que motivem a abertura de processos de impeachment ou outros mecanismos de remoção ${ }^{70}$.

Isso faz com que esse o presidente da Câmara ou Congresso tenha uma enorme influência na remoção presidencial. Se for aliado do presidente, mesmo que não possa impedir pedidos de impeachment, pode retardar seu regular processamento, dando tempo ao presidente para negociar com os parlamentares e com os manifestantes, como pode agendar a votação de abertura do processo para um momento de arrefecimento da crise política. Se estiver na oposição, seu tempo de ação favorecerá os desafiantes, diminuindo os recursos do presidente para angariar apoio.

Posto isso, fica claro que para a perspectiva política o problema na relação Executivo-Legislativo é a razão que leva à retirada do presidente do cargo, quando, dentro de um arranjo institucional determinado, as estratégias adotadas pelo chefe do Executivo e os parlamentares falham em garantir o comportamento colaborativo e os interesses de cada ramo tornam-se inconciliáveis e um busca a retirada do outro. Somando-se à interação de fatores sociais, resulta em uma crise cuja consequência, invariavelmente, é a saída do presidente.

Ao analisarmos o conjunto de fatores explicativos empregado na literatura, somos capazes de extrair a ideia mais básica e geral do conceito de remoção presidencial. Seja qual for a origem do desafio, o custo para a população e para o Congresso em manter o presidente é maior do que o de tentar removê-lo. Contudo, as raízes da

69. PÉREZ-LIÑÁN (2014); LLANOS y MARSTEINTREDET (2010a).

70. FIGUEIREDO y LIMONGI (1999); LIMONGI (2006); AMORIM NETO (2006); SANTOS (2006). 
divergência entre as perspectivas de qual dos fatores tem maior peso e constitui no grande perigo à sobrevivência do presidente ainda precisa ser tratado.

\section{Raízes da Divergência: metodologia e mensuração}

Um consenso entre as perspectivas dentro da literatura parece ainda distante. Cada lado traz ao debate não apenas explicações sólidas, mas também resultados empíricos que corroboram suas afirmações. Essa divergência impede a construção de um quadro teórico adequado que permita o desenvolvimento do campo e um entendimento mais sistemático do fenômeno de saídas prematuras.

As razões para essa divergência ocorrem porque as pesquisas do campo assumem uma homogeneidade entre os casos de remoção presidencial, quando, de fato, apresentam uma considerável heterogeneidade entre fatores importantes. Essa homogeneidade refere-se ao grau dos fatores políticos e sociais, isto é, a manifestação das ruas, o nível de acirramento entre Executivo e Legislativo, o impacto dos escândalos de corrupção não haveria uma variação no grau desses fatores entre os casos analisados. Os estudos tentam encontrar um padrão entre múltiplos casos utilizando análises quantitativas para descobrir o impacto de um conjunto de variáveis semelhantes. Ao tratá-los de forma homogênea, as pesquisas esperam encontrar uma similaridade de antecedentes e resultados para todas as remoções presidenciais que não ocorrem ${ }^{71}$.

Ademais, a diferença na mensuração das variáveis e critérios de seleção da amostra, somado a aplicação de metodologias distintas para testar as principais hipóteses, contribuem para a divergência, agravada pelo número baixo de casos existentes de um fenômeno de complexidade elevada, o que dificulta a análise dos efeitos médios dos fatores analisados. Não obstante, o foco excessivo das pesquisas na América Latina pode esconder características específicas do presidencialismo da região, especialmente pelo fato dos casos ocorridos concentrarem-se em alguns países da América do Sul, dos quais alguns são reincidentes em remover o presidente (Argentina, Equador, Bolívia e Paraguai).

Ao assumir precondições similares, as pesquisas não se atentam para duas dimensões importantes: a) a motivação da oposição em desafiar o presidente; b) a variação do conjunto institucional e democrático entre as remoções ${ }^{72}$.

A motivação principal do desafio pode ser o desvio de conduta do presidente, como casos de corrupção que o envolvam diretamente. Nessas hipóteses, a ferramenta constitucional no presidencialismo para sancionar o comportamento ilegal ou 
inconstitucional do chefe do Executivo à disposição do Congresso é o impeachment ${ }^{73}$. Nesse cenário, os principais desafiantes serão os parlamentares e, por conseguinte, é mais provável que os atores políticos sejam o fator de maior peso na remoção ao invés dos protestos de rua ${ }^{74}$.

Contudo, a motivação dos desafios pode se dar por uma divergência extrema de preferências sobre políticas públicas. Uma má administração do Executivo, expressada nas quedas de taxa de popularidade e índices socioeconômicos, não configura conduta ilegal ou inconstitucional do presidente que permita aos oposicionistas ativarem o impeachment. Por essa razão, nessas hipóteses, é mais provável que os desafios sejam oriundos das ruas e o peso dos protestos tende a ser o principal fator na remoção presidencial 75 .

Em relação às regras democráticas, a premissa de homogeneidade desconsidera a variação institucional entre os casos. Se o desenho institucional molda as estratégias e comportamento dos atores, as diferenças institucionais entre os casos geram estratégias e comportamentos diferentes para o Executivo e Legislativo. Ademais, um arcabouço institucional débil, fonte do problema de estabilidade de governo, é incapaz de manter os atores comprometidos com as regras do jogo, gerando um comportamento predatório entre eles, afetando o próprio sistema político. Nesse cenário, práticas como a tentativa sistemática de derrubada de presidentes pela oposição e a descrença da população com a capacidade de solucionar problema das instituições governamentais acabam sendo a regra, com intensos protestos de rua e disputas desleais pelo controle de governo ${ }^{76}$.

Ao tratarmos sobre a mensuração e operacionalização das variáveis, evidencia-se a diferença nos critérios entre os trabalhos. A unidade de análise utilizada é administração/país-ano (e.g.: Collor/Brasil, 1992) ${ }^{77}$. Como a remoção presidencial é o fenômeno da saída prematura do presidente sem a ruptura democrática, o index adotado pelas pesquisas para a classificação dos países como democráticos é o Polity IV, que

73. Há também a declaração de incapacidade e o abandono de cargo que serão discutidas mais adiante.

74. MARSTEINTREDET (2014).

75. PÉREZ-LIÑÁN (2007); MARSTEINTREDET (2014).

76. LLANOS (2010); MUSTAPIC (2010); BUITRAGO (2010); ACOSTA y POLGA-HECIMOVICH (2010); PÉREZ-LIÑÁN (2007).

77. LLANOS y MARSTEINTREDET (2010a); PÉREZ-LIÑÁN (2007); HOCHSTETLER y SAMUELS (2011); HOCHSTETLER y EDWARDS (2009); MARTÍNEZ (2017); KIM (2014); KIM y BAHRY (2008); HOCHSTETLER (2006). 
captura a variação da democracia em cada país ano a ano ${ }^{78}$, ou a classificação do Index para Democracia ${ }^{79}$.

Um dos critérios para a seleção da amostra é o país ser presidencialista ${ }^{80}$ ou semipresidencialista ${ }^{81}$ e ser classificado ao menos no índice +5 pontos no ano em que o presidente foi removido e os sucessores devem ser escolhidos de acordo com a constituição ${ }^{82}$; +6 ou mais pontos em um período de 03 anos, para países que tiveram grande transição democrática e $+3 \mathrm{a}+5$ pontos, no mesmo período, para países que tiveram menor transição democrática ${ }^{83}$; ou países classificados como democráticos ou semidemocráticos pelo Index para Democracia, no período selecionado ${ }^{84}$, que por sua vez varia entre 1974 e $2012^{85}$ e 1990 a $2005^{86}$, na América Latina, com exceção de Kim e Bahry (2008) e Hochstetler e Edwards (2009).

Para os dados de escândalos de corrupção ${ }^{87}$, as pesquisam utilizam como fonte revistas eletrônicas, destacando-se a Latin American Weekly Report (LAWR) como principal fonte, acompanhada da Foreign Broadcast Information Service (FBIS) e, em menor escala, LexisNexis Academic Universe ${ }^{88}$. Contudo, um grupo seleciona as notícias que envolvam pessoalmente o presidente, com evidências concretas ${ }^{89}$ e outro que envolva o presidente ou pessoas de seu círculo interno ${ }^{90}$. A maioria mede em variável

78. HOCHSTETLER y EDWARDS (2009); KIM (2014); KIM y BAHRY (2008); MARTÍNEZ (2017). 79. MAINWARING et al. (2007) classifying political regimes in latin america. In: Regimes and Democracy in Latin America. [s.l.] Oxford University Press, 2007. pp. 51-101.

80. HOCHSTETLER y EDWARDS (2009); PÉREZ-LIÑÁN (2007); MARTÍNEZ (2017); LLANOS y MARSTEINTREDET (2010a).

81. KIM (2014) KIM y BAHRY (2008).

82. HOCHSTETLER y EDWARDS (2009); MARTÍNEZ (2017).

83. KIM (2014); KIM y BAHRY (2008).

84. PÉREZ-LIÑÁN (2007); LLANOS Y MARSTEINTREDET (2010a).

85. HOCHSTETLER (2006); HOCHSTETLER y EDWARDS (2009); KIM y BAHRY (2008); KIM (2014); MARTÍNEZ (2017).

86. LLANOS Y MARSTEINTREDET (2010a); PÉREZ-LIÑÁN (2007).

87. A definição de escândalos de corrupção é a mesma utilizada na seção 1.1.2.

88. LLANOS (2010); HOCHSTETLER (2006); HOCHSTETLER y EDWARDS (2009); KIM y BAHRY (2008); KIM (2014); PÉREZ-LIÑÁN (2007); MARTÍNEZ (2017).

89. HOCHSTETLER (2006); HOCHSTETLER y EDWARDS (2009).

90. PÉREZ-LIÑÁN (2007); LLANOS (2010); MARTÍNEZ (2017); KIM y BAHRY (2008); KIM (2014). 
binária para a ocorrência ou não de escândalos no período de um ano ${ }^{91}$. Pérez-Liñán (2007), por sua vez, mede os escândalos pela proporção de ocorrências em uma administração pelo número de meses em que o presidente ocupou o cargo.

Para a avaliação da performance econômica, as pesquisas são mais uniformes em relação à operacionalização. A fonte mais utilizada é a base de dados do Banco Mundial e, em alguns casos específicos, órgãos nacionais, como o IBGE. Há várias formas de mensuração dessa variável e as medidas padrões são as mais utilizadas: taxa de crescimento anual do PIB, em uma variável dicotômica de crescimento ou não; o log anual de mudança da taxa de inflação e mudança na taxa mensal de desemprego ${ }^{92}$.

Os protestos de rua possuem mais de uma mensuração e fonte. Assim como os escândalos de corrupção, as pesquisas se valem, em sua maioria, de revistas eletrônicas, como LAWR ${ }^{93}$, Keesing's Contemporary Archives $^{94}$ e LexiNexis ${ }^{95}$. As mensurações utilizadas nas pesquisam captam e diferenciam eventos noticiados como protestos antigoverno (com diferenciação dentre aqueles que pediam ou não a saída do presidente) e greves gerais ${ }^{96}$, com algumas pesquisas estabelecendo um mínimo de participantes $^{97}$.

Sua codificação varia entre uma variável binária, indicando se houve ou não protesto em um ano da administração ${ }^{98}$ e o número total de protestos dentro de um ano ${ }^{99}$. Há ainda a indicação se houve mortes durante as manifestações, com variável binária ${ }^{100}$. Pérez-Liñán (2007) é o único que mensura e codifica a participação de, pelo menos, seis grupos sociais distintos a fim de verificar a formação de uma coalizão social, em uma variável que vai de o a 1 .

91. HOCHSTETLER (2006; 2011); MARTÍNEZ (2017); LLANOS (2010); KIM y BAHRY (2008); KIM (2014).

92. MARTÍNEZ (2017); HOCHSTETLER y EDWARDS (2009); PÉREZ-LIÑÁN (2007); KIM y BAHRY (2008); KIM (2014); ÁLVAREZ y MARSTEINTREDET (2010); LLANOS y MARSTEINTREDET (2010a).

93. PÉREZ-LIÑÁN (2007); HOCHSTETLER (2006); LLANOS y MARSTEINTREDET (2010a).

94. HOCHSTETLER y EDWARDS (2009), MARTÍNEZ (2017); KIM y BAHRY (2008).

95. KIM (2014).

96. KIM y BAHRY (2008); LLANOS y MARSTEINTREDET (2010a); MARTÍNEZ (2017); KIM (2014).

97. MARTÍNEZ (2017); HOCHSTETLER y EDWARDS (2009); KIM (2014).

98. KIM y BAHRY (2008).

99. HOCHSTETLER (2006); KIM (2014); PÉREZ-LIÑÁN (2007).

100. HOCHSTETLER y EDWARDS (2009); MARTÍNEZ (2017). 
Em relação aos fatores políticos, diante da dificuldade em encontrar fontes equivalentes entre os países para a coleta dos dados, as pesquisam utilizam-se de fontes externas, como a base de dados de instituições políticas do Banco Mundial ${ }^{101}$, Democratic Elections Around The Word ${ }^{102}$ ou fontes próprias ${ }^{103}$ e de outros estudos ${ }^{104}$ para a medição de governos divididos e de apoio partidário no Congresso.

Como na amostra das pesquisas verifica-se a existência de países bicamerais e alguns unicamerais, mede-se o apoio partidário nas duas casas legislativas ou da Assembleia, quando há apenas uma casa, medindo o número de cadeiras que o governo, a oposição e partidos não alinhados possuem, a partir de dados de coalizão ${ }^{105}$.

As pesquisas que utilizam a variável de governo dividido ou de divisão interna dentro do governo e a existência de crises na administração, usam dados da LAWR e Banco Mundial, operacionalizando em variável binária para ano de administração. Para as informações de remoção por via institucional, como o patamar de votos necessários para o impeachment ou declaração de incapacidade, as pesquisas coletaram os dados diretamente das constituições ou Constitutions of the Countries of The World Online $^{106}$. Por não haver indicadores capazes de medir as estratégias presidenciais, as pesquisas que levam em conta esse fator analisam a partir de estudos de caso ${ }^{107}$.

O segundo critério para a seleção da amostra está diretamente relacionado com as diferentes metodologias aplicadas na literatura. Alguns trabalhos selecionam os casos pela variável dependente, isto é, pela remoção do presidente, desconsiderando casos em que o presidente permaneceu no cargo a despeito de tentativas de forçar sua saída. Ou seja, há pesquisas que ignoram a existência de desafios contra o presidente $^{108}$, examinando, dessa forma, apenas tentativas bem sucedidas e tendo como contrafactual todo o conjunto de presidentes que completaram seus mandatos indistintamente.

101. KIM (2014); KIM y BAHRY (2008); MARTÍNEZ (2017).

102. NEGRETTO (2006); HOCHSTETLER y EDWARDS (2009); MARTÍNEZ (2017).

103. PÉREZ-LIÑÁN (2007).

104. LLANOS y MARSTEINTREDET (2010a); NEGRETTO (2006).

105. NEGRETTO (2006); KIM y BAHRY (2008); PÉREZ-LIÑÁN (2007); LLANOS y MARSTEINTREDET (2010a).

106. PÉREZ-LIÑÁN (2007); KIM (2014).

107. LLANOS y MARSTEINTREDET (2010a); PÉREZ-LIÑÁN (2007).

108. BAUMGARTNER y KADA (2003); KIM y BAHRY (2008). 
Ao ignorar a existência dos desafios, perde-se informações importantes, dentro do grupo de presidentes desafiados, se aqueles que não sobreviveram compartilham desproporcionalmente fatores de risco com aqueles que permaneceram apesar dos esforços para suas saídas ${ }^{109}$.

As pesquisam que levam em conta a existência de desafios, seja de rua ou institucional $^{110}$, selecionam, assim, duas variáveis dependentes. Hochstetler e Edwards (2009), partindo desse ponto, aplicam o modelo de duas equações Heckman probit, ao entender que os fatores e atores que atuam no desafio e na remoção são diferentes e ocorrem em momentos distintos na equação. As demais pesquisas, mesmo aquelas que não diferenciam desafios e remoções, aplicam o modelo de regressão logística de eventos $\operatorname{raros}^{111}$.

Dadas todas essas diferenças, a literatura de remoção presidencial encontra-se com um enorme problema de mensuração. Sob a justificativa de tentar aumentar o número de eventos, as pesquisas negligenciam um critério que melhor diferencie e selecione os casos de remoção. A seguir vamos entrar no debate normativo presente na literatura.

\section{Impeachment e outros mecanismos institucionais de remoção do presidente}

Dissemos acima que a forma de remoção presidencial varia por questões de contingência e expediente. Essa variabilidade ocorre, pois, no sistema presidencialista, encontramos mais de uma forma institucional de remover o presidente antes do fim do mandato. Em regra, as constituições presidenciais preveem o impeachment e, em menor grau, a declaração de incapacidade e abandono de cargo. A renúncia do presidente também gera a interrupção do governo, mas não é uma forma exclusiva do presidencialismo. As características e procedimentos específicos de cada um interferem diretamente na construção do "escudo legislativo" e na avaliação do cenário político pelos desafiantes e desafiados.

A renúncia do chefe do Executivo é uma das saídas possíveis para as crises presidenciais. Quando as manifestações populares contrárias à permanência do chefe do Executivo se intensificam e, no Legislativo, não é mais possível a formação de uma coalizão governamental majoritária ou a oposição foi capaz de formar uma coalizão que detenha a maioria, o presidente, antevendo a impossibilidade de sobreviver aos

109. PÉREZ-LIÑÁN (2007); HOCHSTETLER y EDWARDS (2009); HOCHSTETLER (2006).

110. PÉREZ-LIÑÁN (2007); HOCHSTETLER y EDWARDS (2009); HOCHSTETLER (2006); KIM (2014); LLANOS y MARSTEINTREDET (2010a).

111. PÉREZ-LIÑÁN (2007); LLANOS y MARSTEINTREDET (2010a); KIM (2014); KIM y BAHRY (2008). 
desafios, renuncia antes da instauração de procedimentos institucionais de remoção, negociando com os opositores sua saída a fim de evitar as consequências políticas da cassação $^{112}$.

Pouco conhecida, a declaração de incapacidade é um mecanismo institucional previsto em algumas constituições presidencialistas que permite ao Congresso remover o presidente do cargo após declarar sua incapacidade física ou mental para governar o país. O abandono de cargo é uma variante da declaração de incapacidade ao permitir remover o presidente por ausência permanente da presidência. Essas regras foram pensadas como maneiras de substituir o chefe do Executivo que estivesse vivo, mas incapaz de exercer suas funções, não sendo necessário para isso o cometimento de algum crime ${ }^{113}$.

Porém, nos episódios em que presidentes foram removidos por esses mecanismos, as constituições não exigiam procedimentos especiais para ativá-los. Isto é, não havia a necessidade de comprovação por exames médicos e psicológicos para atestar a incapacidade do presidente ou a existência de regra que definisse a ausência permanente. A competência era exclusiva do Legislativo para fazer essas avaliações, o que significava que seria decidido de acordo com o humor dos parlamentares, em uma votação que requeria apenas uma maioria absoluta do Congresso ${ }^{114}$.

O caso mais emblemático de remoção por declaração de incapacidade foi o do expresidente Abdalá Bucaram, removido em 1997, após vencer as eleições equatorianas de 1996, enquanto o ex-presidente venezuelano Carlos Pérez foi removido em 1993 depois de ter sido declarado ausente da presidência. Em ambos os casos, os presidentes enfrentavam intensos protestos de rua pedindo suas saídas e lidavam com parlamentos hostis. Apesar de majoritária, a oposição, nos dois episódios, não contava com votos suficientes para o impeachment (supermaioria de $2 / 3$ do Congresso) e a solução encontrada foi recorrer à declaração de incapacidade, no primeiro caso, e ao abandono de cargo, no segundo, por serem menos exigentes quanto aos procedimentos ${ }^{115}$.

Ao trazer termos vagos e procedimentos pouco restritivos, essas constituições permitiram a manipulação política pelos opositores, desvirtuando seu objetivo inicial e aumentaram os custos do presidente em formar o "escudo legislativo", pois era preciso contar com um número maior de aliados a fim de barrar as manobras contrárias à sua permanência. Em outros países que possuem esses mecanismos, porém com re-

112. MARSTEINTREDET y BERNTZEN (2008); PÉREZ-LIÑÁN (2007); MUSTAPIC (2010).

113. MARSTEINTREDET y BERNTZEN (2008); PÉREZ-LIÑÁN (2007).

114. PÉREZ-LIÑÁN (2007); MARSTEINTREDET y BERNTZEN (2008).

115. ACOSTA y POLGA-HECIMOVICH (2010); BAUMGARTNER y KADA (2003); LALANDER (2010); MARSTEINTREDET y BERNTZEN (2008); PÉREZ-LIÑÁN (2007). 
gras mais restritivas, como o Chile e Estados Unidos, a utilização está mais protegida da influência de crises presidenciais e de interpretações elásticas ${ }^{116}$.

O impeachment é, por excelência, o principal procedimento à disposição do Congresso para remover o presidente do cargo, presente virtualmente em todas as constituições presidenciais. Esse mecanismo pode ser definido como o julgamento pelo Legislativo contra o presidente acusado de cometer crime político, definido em lei como crime de responsabilidade, cuja sanção é a cassação do mandato e a perda de seus direitos políticos e que, em ao menos uma etapa, esse procedimento passe pelo crivo do Legislativo ${ }^{117}$.

Seu desenho constitucional, na classificação proposta por Kada (2003), pode ser definido como sistema "dominado pela legislatura", o mais comum e propagado entre países presidencialistas, e "dominado pelo Judiciário". No primeiro sistema, apenas o Poder Legislativo tem a prerrogativa de autorizar e julgar o impeachment, ao passo que no segundo sistema a autorização cabe ao Congresso e o julgamento é conduzido pelo Poder Judiciário Os impeachments presidenciais são sempre iniciados pela legislatura, o que o torna um procedimento essencialmente político ao invés de legal, pois quem irá decidir o destino do chefe do Executivo são atores políticos com interesses próprios $^{118}$.

No impeachment, ao menos uma das etapas - autorização ou julgamento - requer um patamar de votação com supermaiorias qualificadas. Porém, mesmo diante de normas mais restritas para seu uso, o número de presidentes que sofreram impeachment aumentou nos últimos anos. Isso significa que o papel das regras constitucionais deve ser avaliado à luz da capacidade do presidente em mobilizar apoio entre membros do Congresso para construir o "escudo legislativo" 119.

\section{Considerações finais}

O artigo se propôs a fazer um balanço da literatura de remoção presidencial. A saída de presidentes passou a receber um tratamento sistemático apenas a partir dos anos 200o, o que gera uma série de debates ainda em disputa e a necessidade de se superar obstáculos teóricos e empíricos. Os trabalhos do campo alcançaram um entendimento considerável sobre o fenômeno e conseguiram estabelecer as condições que tornam um presidente eleito democraticamente vulneráveis a sua permanência.

116. PÉREZ-LIÑÁN (2007); MARSTEINTREDET y BERNTZEN (2008).

117. BAUMGARTNER y KADA (2003); MARSTEINTREDET y BERNTZEN (2008); PÉREZLIÑÁN (2007).

118. BAUMGARTNER y KADA (2003); PÉREZ-LIÑÁN (2007).

119. BAUMGARTNER y KADA (2003); KIM (2014); PÉREZ-LIÑÁN (2007). 
A confirmação de que estamos numa era de "nova instabilidade política", com o virtual desaparecimento de quebras de regimes democráticos foi um avanço nas democracias da Terceira Onda. Contudo, isso não significou o fim de crises presidenciais. Vimos que o campo traz um conjunto de fatores políticos e sociais que afetam as chances do chefe do Executivo em se manter no cargo.

Fatores como a exposição de escândalos de corrupção envolvendo a figura do presidente, sua exposição sistemática pelos meios de comunicação de massa e a influência de adversidades econômicas desestabilizam o ambiente político e são capazes de motivar desafios ao presidente vindo de pressão das ruas, de ativismo legislativo ou de uma junção de ambos que podem culminar com a remoção presidencial quando combinados com fatores como o status minoritário do partido ou coalizão do presidente no Congresso, a deterioração da relação Executivo-Legislativo, em que os poderes já não cooperam entre si, e comportamento adotado pelo presidente durante o governo.

A identificação das causas políticas e sociais foi um avanço importante. Contudo, a literatura ainda não chegou a um consenso sobre qual tipo tem maior impacto na sobrevivência do incumbente, com uma divisão clara de perspectivas de ênfase diferentes. Assim como o debate normativa desse fenômeno permanece em aberto. Essas divergências mostram um caminho aberto de pesquisas que deverão pensar soluções para os desafios de se formular um quadro teórico capaz de captar a interação das forças da sociedade civil com as instituições políticas tradicionais, o comportamento estratégico dos parlamentares e das coalizões, o papel exato do vice-presidente e até que ponto as estratégias do presidente selam o seu destino diante das crises.

\section{Referências bibliográfico}

ACOSTA, Andrés y POLGA-HECIMOVICH, John (2010): Parliamentary Solutions to Presidential Crises in Ecuador. En: M. LLANOS y L. MARSTEINTREDET (eds.), Presidential Breakdowns in Latin America: Causes and Outcomes of Executive Instability in Developing Democracies [en línea]. New York: Palgrave Macmillan US, pp. 73-9o. Disponible en: http://link.springer.com/10.1057/9780230105812_5. [Fecha de consulta: 21 mayo 2018].

ÁLVAREZ, Michael y MARSTEINTREDET, Leiv (2010): Presidential and Democratic Breakdowns in Latin America: Similar Causes, Differente Outcomes. En: M. LLANOS y L. MARSTEINTREDET (eds.), Presidential Breakdowns in Latin America: Causes and Outcomes of Executive Instability in Developing Democracies [en línea]. New York: Palgrave Macmillan US, pp. 33-52. . Disponible en: http://link. springer.com/10.1057/9780230105812_3. [Fecha de consulta: 21 mayo 2018]. 
AMORIM NETO, Octavio (2006): Presidencialismo e governabilidade nas Américas. (S.l.: Konrad-Adenauer-Stiftung. ISBN 8522505535).

BATISTA, Mariana (2016). Quem ganha o que e como isso importa? Alocação de ministérios e apoio legislativo no Brasil. 10o. Encontro da ABCP [en línea]. S.l.: s.n., pp. 1-3o. Disponible en: https://cienciapolitica.org.br/system/files/documentos/ eventos/2017/o4/quem-ganha-que-e-como-isso-importa-alocacao-ministerios-e. pdf. [Fecha de consulta: 9 noviembre 2018].

BAUMGARTNER, Jody y KADA, Naoko (2003): Checking excecutive power. Presidential impeachment in comparative perspective. [en línea]. S.l.: Praeger. ISBN 9780275979263. Disponible en: https://books.google.com.br/books?id=1rtFINZ szScC\&printsec $=$ frontcover \&dq $=$ checking +executive + power + presidential + imp eachment + in + comparative + perspective $\&$ hl $=$ pt-BR\&sa $=X \& v e d=o a h U K E w i 7 u-$ 8Hn2KbTAhULhJAKHdkgB_AQ6AEIIjAA\#v=onepage\&q=checkingexecutive power presiden. [Fecha de consulta: 15 abril 2017].

BAUMGARTNER, Jody y KADA, Naoko (2003): Checking Executive Power: Presidential Impeachment in Comparative Perspective [en línea]. S.l.: Praeger. ISBN 9780275979263. Disponible en: https://books.google.com.br/books?id=1rtFINZsz $\mathrm{ScC} \&$ printsec $=$ frontcover $\& \mathrm{dq}=$ checking + executive + power $\& \mathrm{hl}=\mathrm{pt}-\mathrm{BR} \& \mathrm{sa}=\mathrm{X} \&$ ved=oahUKEwji8Jvm8srWAhVGGZAKHSS8CLoQ6AEIJjAA\#v=onepage\&q=c hecking executive power\&f=false. [Fecha de consulta: 29 septiembre 2017].

BUITRAGO, Miguel (2010): Civil Society, Social Protest, and Presidential Breakdowns in Bolivia. En: M. LLANOS y L. MARSTEINTREDET (eds.), Presidential Breakdowns in Latin America: Causes and Outcomes of Executive Instability in Developing Democracies [en línea]. New York: Palgrave Macmillan US, pp. 91107. Disponible en: http://link.springer.com/10.1057/9780230105812_6. [Fecha de consulta: 21 mayo 2018].

CHEIBUB, José (2002): Minority Governments, Deadlock Situations, and the Survival of Presidential Democracies. Comparative Political Studies [en línea], vol. 35, no. 3, pp. 284-312. ISSN 0010-4140. DOI 10.1177/0010414002035003002. Disponible en: http://cps.sagepub.com/cgi/doi/10.1177/o010414002035003002.

CHEIBUB, José (2007): Presidentialism and Democratic Performance. En: A. REYNOLDS (ed.), The Architecture of Democracy: Constitucional Design, Conflit Management, and Democracy. S.l.: Oxford Political Theory, ISBN o-19-9246459.

CHEIBUB, José y LIMONGI, Fernando (2002): Democratic Institutions and Regime Survival : Parliamentary and Presidential Democracies Reconsidered. Annual Review of Political Science [en línea], año 5, No. 1, pp. 151-179. ISSN 1094-2939. DOI 10.1146/annurev.polisci.5.102301.084508. Disponible en: http://www.annualreviews.org/doi/abs/10.1146/annurev.polisci.5.102301.084508. 
FIGUEIREDO, Argelina (2007): Government Coalitions in Brazilian democracy. Brazilian Political Science Review, año 1, No 2, pp. 182-216.

FIGUEIREDO, Argelina (2010): The Collor Impeachment and Presidential Government in Brazil. En: M. LLANOS y L. MARSTEINTREDET (eds.), Presidential Breakdowns in Latin America: Causes and Outcomes of Executive Instability in Developing Democracies [en línea]. New York: Palgrave Macmillan US, pp. 111127. Disponible en: http://link.springer.com/10.1057/9780230105812_7. [Fecha de consulta: 21 mayo 2018].

FIGUEIREDO, Argelina y LIMONGI, Fernando (1999): Executivo e Legislativo na nova ordem constitucional [en línea]. S.l.: Fundação Getúlio Vargas. . ISBN 8522502919. Disponible en: https://books.google.com.br/books?id=mtvcAAAAC AAJ\&dq=executivo+e+legislativo + na + nova + ordem + constitucional + fernando+li mongi + argelina + figgueiredo\&hl=pt-BR\&sa=X\&ved =oahUKEwiwwvOpnM_TAhUEEJAKHSGcCroQ6AEIIjAA. [Fecha de consulta: 1 mayo 2017].

HOCHSTETLER, Kathryn (2006): Rethinking Presidentialism: Challenges and Presidential Falls in South America. Comparative Politics [en línea], año 38, No4, pp. 401-418. ISSN 00104159. DOI 10.2307/20434009. Disponible en: http://www.jstor. org/stable/10.2307/20434009?origin $=$ crossref.

HOCHSTETLER, Kathryn (2011): The Fates of Presidents in Post-Transition Latin America: From Democratic Breakdown to Impeachment to Presidential Breakdown. Journal of Politics in Latin America [en línea], año 3, No 1, pp. 125-141. ISSN 1868-4890. Disponible en: www.jpla.org. [Fecha de consulta: 15 noviembre 2016].

HOCHSTETLER, Kathryn y EDWARDS, Margaret (2009): Failed Presidencies: Identifiying and Explaining a South American Anomaly. Journal of Politics in Latin America, año 2, pp. 31-57.

HOCHSTETLER, Kathryn y SAMUELS, David (2011): Crisis and Rapid Reequilibration: The Consequences of Presidential Challenge and Failure in Latin America. Comparative Politics, año 43, No 2, pp. 127-145. ISSN 00104159. DOI 10.5129/001041511793931834.

HUNTINGTON, Samuel (1994): A Terceira Onda - A democratização no final do século XX. (S.l. Atica. ISBN 8508046928).

KIM, Young (2014): Impeachment and presidential politics in new democracies. Democratization [en línea], año 21, No 3, pp. 519-553. ISSN 1351-0347. DOI 10.1080/13510347.2012.751973. Disponible en: http://www.tandfonline.com/doi/ab S/10.1080/13510347.2012.751973. [Fecha de consulta: 1 mayo 2017].

KIM, Young y BAHRY, Donna (2008): Interrupted Presidencies in Third Wave Democracies. The Journal of Politics, año 70, No 03 , pp. 807-822. ISSN 0022-3816. DOI 10.1017/Soo22381608080778. 
LALANDER, Rickard (2010): The Impeachment of Carlos Andrés Pérez and the Collapse of Venezuelan Partyarchy. En: M. LLANOS y L. MARSTEINTREDET (eds.), Presidential Breakdowns in Latin America: Causes and Outcomes of Executive Instability in Developing Democracies [en línea]. New York: Palgrave Macmillan US, pp. 129-145. Disponible en: http://link.springer.com/10.1057/9780230105812_8. [Fecha de consulta: 21 mayo 2018].

LIMONGI, Fernando (2006): A Democracia no Brasil. Novos Estudos: Cebrap [en línea], año 76, pp. 17-41. DOI So101-33002006000300002.

LINZ, Juan (1990): The Perils of Presidentialism. Journal of Democracy [en línea], año 1, No 1, pp. 51-69. ISSN 1086-3214. DOI 10.1353/jod.1990.0011. Disponible en: http://muse.jhu.edu/journals/jod/summary/voo1/1.1linz.html. [Fecha de consulta: 27 septiembre 2017].

LINZ, Juan (1994): Presidential or Parlamentary Democracy: Does It Make a Difference? En: J.J. LINZ y A. VALENZUELA (eds.), The Failure of Presidential Democracy [en línea]. S.l.: Johns Hopkins University Press, pp. 3-90. ISBN 9780801846403. Disponible en: https://books.google.com.br/books?id=e5dkxDhDjCoC\&printsec $=\mathrm{fr}$ ontcover $\& d q=$ the + failure + of + presidential + democracy $\& h l=p t-B R \& s a=X \& v e d=$ oahUKEwimvcXehcvWAhWBfpAKHZSEAkoQ6AEIKTAA\#v=onepage\&q=the failure of presidential democracy\&f=false. [Fecha de consulta: 29 septiembre 2017].

LINZ, Juan (1978): The Breakdown of Democratic Regimes: Crisis, breakdown and; reequilibration [en línea]. S.l.: Johns Hopkins University Press. ISBN o80182009X. Disponible en: https://books.google.com.br/books?id=_vfkp3sWAyIC\&dq=the breakdown of democratic regimes\&hl=pt-BR\&source=gbs_book_other_versions. [Fecha de consulta: 27 septiembre 2017].

LLANOS, Mariana (2010): Presidential Breakdowns in Argentina. En: M. LLANOS y L. MARSTEINTREDET (eds.), Presidential Breakdowns in Latin America: Causes and Outcomes of Executive Instability in Developing Democracies [en línea]. New York: Palgrave Macmillan US, pp. 55-71. Disponible en: http://link.springer. com/10.1057/9780230105812_4. [Fecha de consulta: 21 mayo 2018].

LLANOS, Mariana y MARSTEINTREDET, Leiv (2010a): Conclusions: Presidential Breakdowns Revisited. En: M. LLANOS y L. MARSTEINTREDET (eds.), Presidential Breakdowns in Latin America: Causes and Outcomes of Executive Instability in Developing Democracies [en línea]. New York: Palgrave Macmillan US, pp. 213-228. Disponible en: http://link.springer.com/10.1057/9780230105812_13. [Fecha de consulta: 21 mayo 2018]. 
LLANOS, Mariana y MARSTEINTREDET, Leiv (2010b): Introduction: Presidentialism and presidential Breakdowns in Latin America. En: M. LLANOS y L. MARSTEINTREDET (eds.), Presidential Breakdowns in Latin America: Causes and Outcomes of Executive Instability in Developing Democracies [en línea]. New York: Palgrave Macmillan US, pp. 1-13. ISBN 9780230105812. Disponible en: http:// link.springer.com/10.1057/9780230105812_1. [Fecha de consulta: 21 mayo 2018].

LLANOS, Mariana y MARSTEINTREDET, Leiv (2010c): Presidential Breakdowns in Latin America: Causes and Outcomes of Executive Instability in Developing Democracies. (S.1.: Palgrave Macmillan. ISBN 978-0-230-61819-0).

MAINWARING, Scott y SHUGART, Matthew (1997): Juan Linz, Presidentialism, and Democracy: A Critical Appraisal. Comparative Politics, año 29, No 4, pp. 449-471.

MARSTEINTREDET, Leiv (2014): Explaining variation of executive instability in presidential regimes: Presidential interruptions in Latin America. International Political Science Review [en línea], año 35, No 2, pp. 173-194. ISSN 01925121. DOI 10.1177/0192512112459548. Disponible en: http://ips.sagepub.com/cgi/ doi/10.1177/0192512112459548. [Fecha de consulta: 15 noviembre 2016].

MARSTEINTREDET, Leiv (2014): Explaining variation of executive instability in presidential regimes: Presidential interruptions in Latin America. International Political Science Review [en línea], año 35, No 2, pp. 173-194. ISSN o1925121. DOI 10.1177/0192512112459548. Disponible en: http://ips.sagepub.com/cgi/ doi/10.1177/0192512112459548. [Fecha de consulta: 15 noviembre 2016].

MARSTEINTREDET, Leiv y BERNTZEN, Einar (2008): Reducing the perils of presidentialism in Latin America through presidential interruptions. Comparative Politics [en línea], año 41, No 1, pp. 83-101. ISSN 00104159. DOI 10.5129/o01041508X1 2911362383714. Disponible en: http://www.jstor.org/stable/20434106.

MARTÍNEZ, Christopher (2017): Presidential survival in South America: Rethinking the role of democracy. International Political Science Review [en línea], año 38, $\mathrm{N}^{\circ}$ 1, pp. 40-55. ISSN 0192-5121. DOI 10.1177/0192512115604904. Disponible en: http://ips.sagepub.com/cgi/doi/10.1177/0192512115604904.[Fecha de consulta: 15 noviembre 2016].

MUSTAPIC, Ana María (2010): Presidentialism and Early Exits: The Role of Congress. En: M. LLANOS y L. MARSTEINTREDET (eds.), Presidential Breakdowns in Latin America: Causes and Outcomes of Executive Instability in Developing Democracies [en línea]. New York: Palgrave Macmillan US, pp. 17-32. Disponible en: http://link.springer.com/10.1057/9780230105812_2. [Fecha de consulta: 21 mayo 2018]. 
NEGRETTO, Gabriel (2006): Minority Presidents and Democratic Performance in Latin America. Latin American Politics and Society [en línea], año 48, No 3, pp. 6392. ISSN 15314.26X. DOI 10.1111/j.1548-2456.2006.tboo356.x. Disponible en: http:// doi.wiley.com/10.1111/j.1548-2456.2006.tboo356.x.

NOVARO, Marcos (2015): Representação e Ordem Pública nas Crises Presidenciais Latino-americanas. En: A. GURZA LAVALLE, A. de VITA y C. ARAÚJO (eds.), O papel da teoria política contemporânea : justiça, constituição, democracia e representação [en línea]. S.l.: s.n., pp. 447. ISBN 8579393450. [Fecha de consulta: 5 abril 2018].

PÉREZ-LIÑÁN, Aníbal (2007): Presidential Impeachment and the New Political Instability in Latin America. 1st. (S.l.: Cambridge University Press. ISBN 978-0-51128945-3).

PÉREZ-LIÑÁN, Aníbal (2014): A Two-Level Theory of Presidential Instability. Latin American Politics and Society, año. 56, No. 1, pp. 34-54. ISSN 1531426X. DOI 10.1111/j.1548-2456.2014.00220.x.

PÉREZ-LIÑÁN, Aníbal y POLGA-HECIMOVICH, John (2017): Explaining military coups and impeachments in Latin America. Democratization [en línea], año 24, $\mathrm{N}^{\circ}$ 5, pp. 839-858. ISSN 174389oX. DOI 10.1080/13510347.2016.1251905. Disponible en: https://www.tandfonline.com/doi/full/10.108o/13510347.2016.1251905. [Fecha de consulta: 16 noviembre 2018].

PESSOA, Bruno (2019): Por que caem? O fenômeno da cassação de prefeitos pela câmaras municipais. DOI: 10.11606/D.8.2019.tde-30072019-141641. São Paulo: Faculdade de Filosofia, Letras e Ciências Humanas, Universidade de São Paulo. Dissertação de Mestrado em Ciência Política. [Fecha de consulta: 06 julio 2020].

SANTOS, Fabiano (2006): Governos de Coalizão no Sistema Presidencial. O Caso do Brasil sob a Égide da Constituição de 1988. En: F. ANASTASIA y L. AVRITZER (eds.), Reforma Política no Brasil. Belo Horizonte: Editora UFMG, pp. 223-238.

SHUGART, Matthew Soberg y CAREY, John (1992): Presidents and Assemblies: Constitucional Design and Electoral Dynamics. 1st editio. (New York: Cambridge University Press. ISBN 9788578110796).

VALENZUELA, Arturo (2004): Latin American Presidencies Interrupted. Journal of Democracy, año. 15, No. 4, pp. 5-19. ISSN 1086-3214. DOI 10.1353/jod.2004.0075. 